\title{
Acute posterior multifocal placoid pigment epitheliopathy complicated by central retinal vein occlusion
}

\author{
D G CHARTERIS, V KHANNA, AND B DHILLON \\ From the Princess Alexandra Eye Pavilion, Royal Infirmary of Edinburgh
}

SUMMARY A case of acute posterior multifocal placoid pigment epitheliopathy (APMPPE) complicated by a central retinal vein occlusion five weeks after presentation is described. After eight months' follow-up there was mild residual visual impairment, macular scarring, and angiographic changes. The association of these two conditions is discussed.

Acute posterior multifocal placoid pigment epitheliopathy (APMPPE) was first described by Gass in 1968.' Since then there have been many clinical descriptions of the disease, but the aetiology remains elusive. A substantial proportion of cases have an associated viral-like prodromal illness, and one case of APMPPE associated with confirmed adenovirus type 5 infection has been reported. ${ }^{2}$ Associations have also been made with systemic inflammatory conditions-erythema nodosum,,$^{34}$ sarcoid, ${ }^{5}$ thyroiditis, ${ }^{6}$ nephritis, ${ }^{7}$ and cerebral vasculitis. ${ }^{\text {z-12 }}$

\section{Case report}

A 28-year-old woman presented to the eye casualty department with complaints of dull frontal headache of two days' duration and deterioration in central vision in her right eye for 24 hours. She was otherwise well and was not taking any medication. The only significant past history was an episode of parietofrontal headache eight years previously; investigations at that time, including a CT brain scan, gave normal results.

Examination revealed visual acuities to be $6 / 36$ right eye and 6/4 left eye unaided. The anterior segments appeared normal. The right fundus had cream coloured placoid lesions, $1 / 2$ to 1 disc diameter, scattered across the posterior pole mainly in the superior half (Fig. 1). The macula was notably oedematous. The left fundus was entirely normal.

Correspondence to Mr D G Charteris, Princess Alexandra Eye Pavilion, Royal Infirmary of Edinburgh, Chalmers Street, Edinburgh EH3 9HA.
A diagnosis of acute posterior multifocal placoid pigment epitheliopathy was made.

Intravenous fluorescein angiography showed early hypofluorescence and late hyperfluorescence of the lesions (Figs. 2, 3) typical of APMPPE. Full and differential blood cell count were normal. The erythrocyte sedimentation rate was $6 \mathrm{~mm} / \mathrm{h}$. Radiography of chest, cranial vault, pituitary fossa, orbits, and optic foraminae showed normal appearances. An enzyme linked immunosorbent assay (ELISA) for toxoplasma was negative. Acute and convalescent serum samples did not show a rising titre to adenovirus, measles, herpes simplex, varicella zoster, cytomegalovirus, or leptospira.

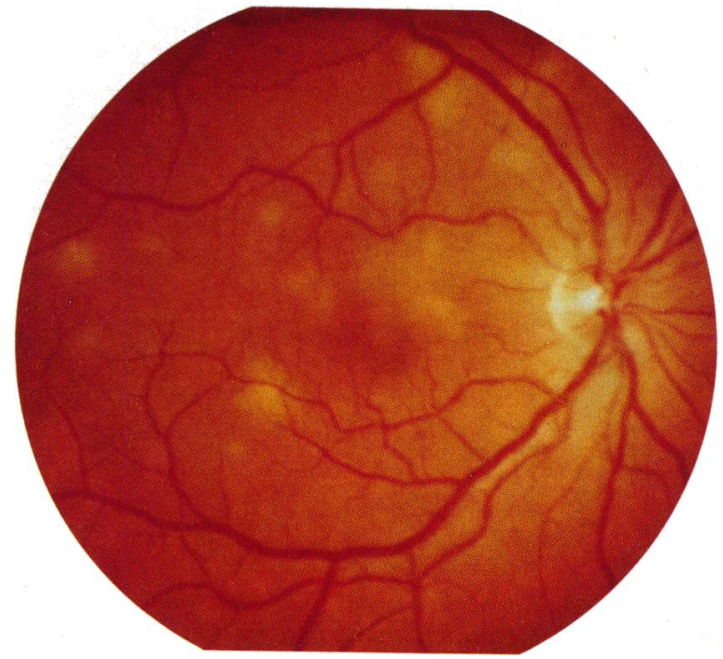

Fig. 1 Right fundus on initial presentation. 


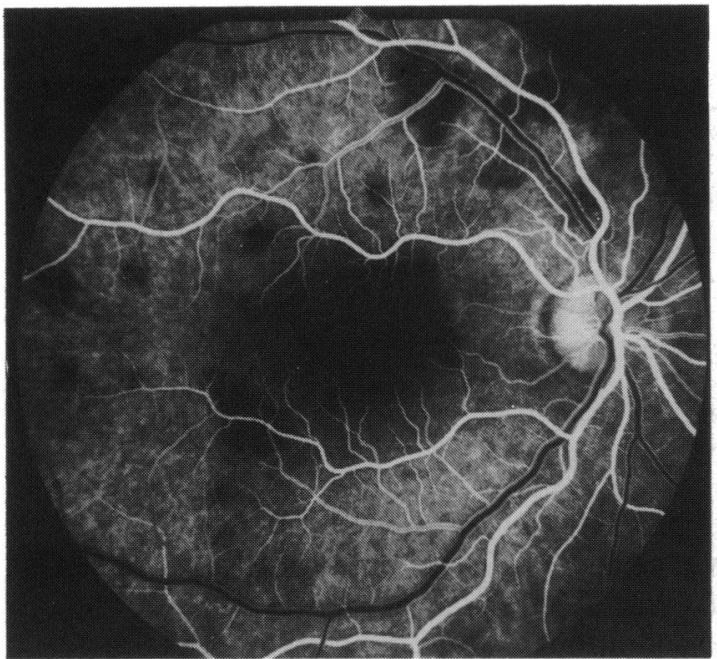

Fig. 2 Early venous phase fluorescein angiogram showing hypofluorescence of placoid lesions.

In view of the macular oedema she was started on prednisolone $80 \mathrm{mg}$ per day, which was slowly reduced over four weeks. During this period the placoid lesions were essentially unchanged. The macular oedema showed some resolution, with reactive pigmentary changes, and the visual acuity improved to $6 / 24$.

When she was examined at the clinic five weeks after her initial presentation, her right fundus had the appearance of a central retinal vein occlusion (Fig. 4). The right optic disc was swollen, and there were

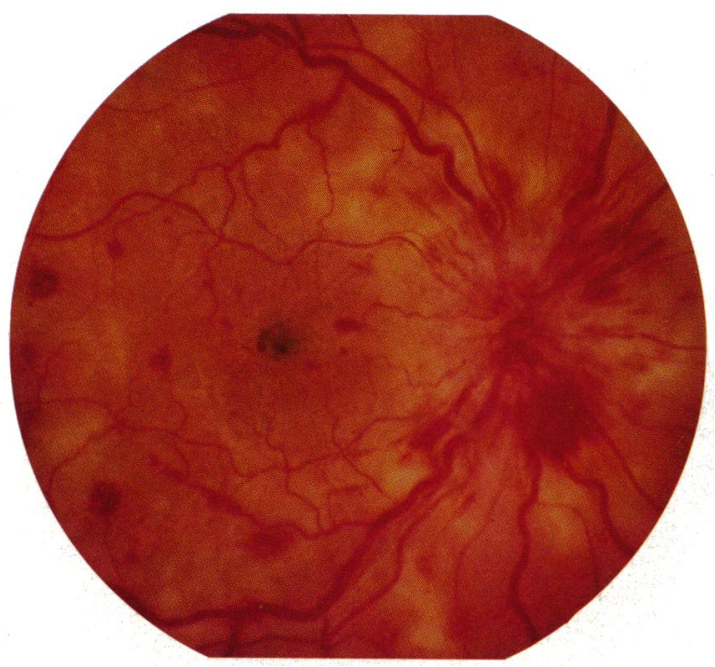

Fig. 4 Right fundus five weeks following initial presentation. A central retinal vein occlusion is superimposed on the placoid lesions.

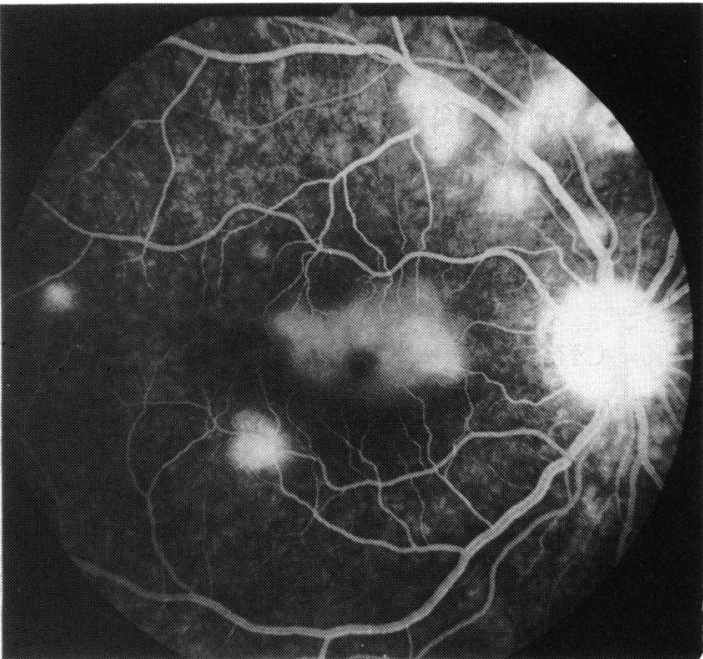

Fig. 3 Late phase fluorescein angiogram showing

hyperfluorescence of placoid lesions and macular oedema.

flame-shaped haemorrhages extending from the disc and scattered linear and blot haemorrhages in all four quadrants. The placoid lesions were now more widespread and were becoming confluent. There was a right relative afferent pupillary defect, and her vision was $6 / 36$ in this eye. The left eye remained unaffected. Fluorescein angiography confirmed the central retinal vein occlusion and the widespread placoid lesions but showed no evidence of retinal vasculitis (Figs. 5, 6). The fundus was not ischaemic, and no treatment was undertaken. The fundal

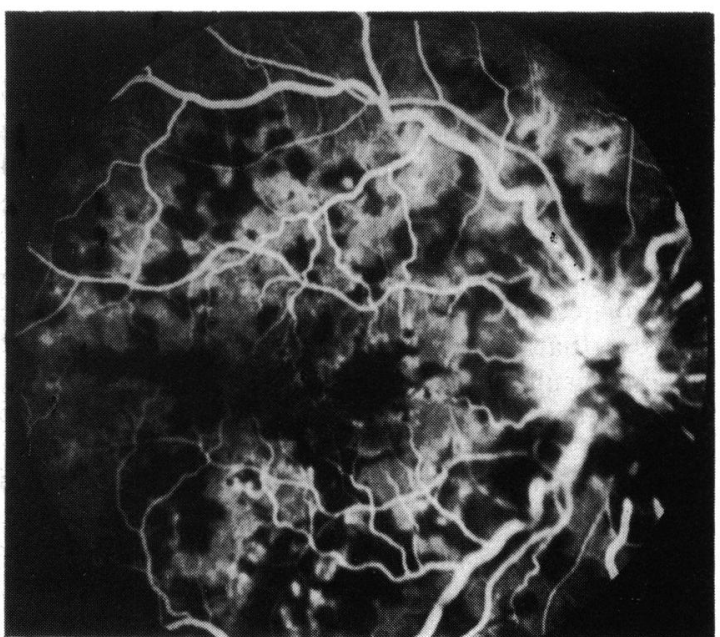

Fig. 5 Venous phase fluorescein angiogram demonstrating masking by retinal haemorrhages and areas of hypofluorescence due to the placoid lesions. 


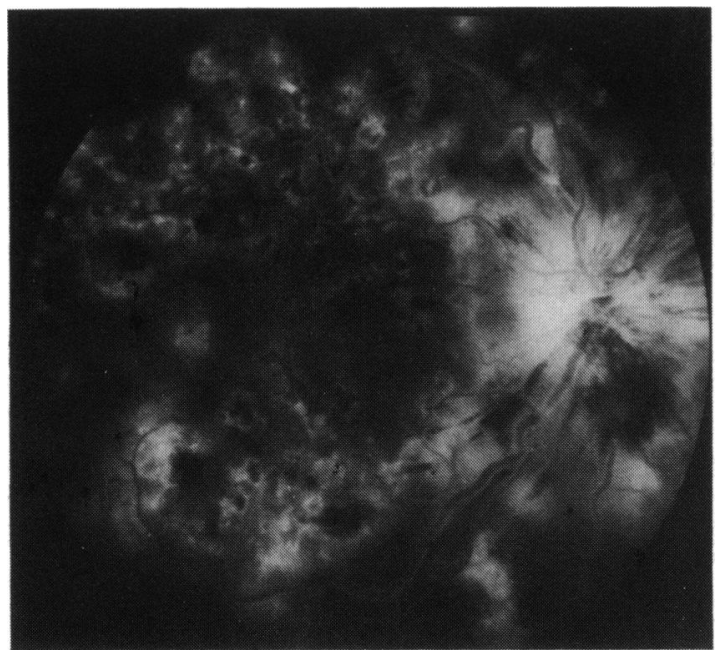

Fig. 6 Late phase angiogram. The placoid lesions now hyperfluoresce at their edges, though some lesions continue to hypofluoresce contrally.

appearance slowly resolved, and the visual acuity improved to $6 / 9$ after eight months' follow-up, when her only complaint was a small central scotoma. Fluorescein angiography at this stage showed patches of hyperfluorescence across the posterior pole (Fig. 7 ), and the macula had a residual pigmented scar (Fig. 8).

\section{Discussion}

The case described showed the typical early features of APMPPE-loss of central vision with multiple cream coloured placoid lesions distributed over the posterior pole at the level of the retinal pigment epithelium. Uniocular cases are unusual but have been reported. ${ }^{1 .-16}$ The initial clinical impression of full visual recovery in $\mathrm{APMPPE}^{\prime}$ has been questioned in more recent work, ${ }^{1314} 17$ and the residual impairment of central vision in this case is attributable to the macular involvement.

There have been no previous reports of central retinal vein occlusion occurring in APMPPE. The observed changes in this case were typical of a central retinal vein occlusion ${ }^{18}$ : there was only a minimal effect on vision and no evidence of fundal ischaemia or retinal vasculitis.

The primary site of the inflammatory process in APMPPE is debated. Some authorities think that the retinal pigment epithelium is the primary focus, ${ }^{1920}$ while others think that there is a choroidal vasculitis with secondary ischaemic changes in the retinal pigment epithelium due to occlusion of choroidal arterioles supplying individual choroidal

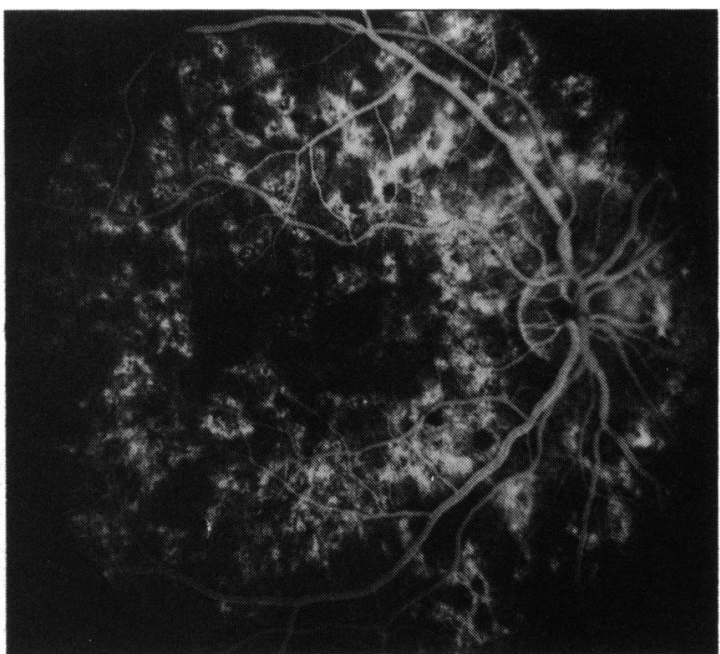

Fig. 7 Fluorescein angiogram eight months after presentation showing patches of hyperfluorescence throughout the posterior pole.

lobules..$^{3478151621-24}$ Many cases of central retinal vein occlusion in young people are thought to be due to inflammation within the vein ${ }^{18}$; optic disc vasculitis presents a similar fundal picture. ${ }^{25}$ The occurrence of the two conditions together lends weight to the theory that APMPPE is due to a choroidal vasculitis and is part of a more widespread systemic inflammatory process. ${ }^{3-12}$ The reported association of APMPPE with retinal vasculitis and papillitis may be part of the same pathological process. ${ }^{21}$

It is perhaps surprising therefore that central

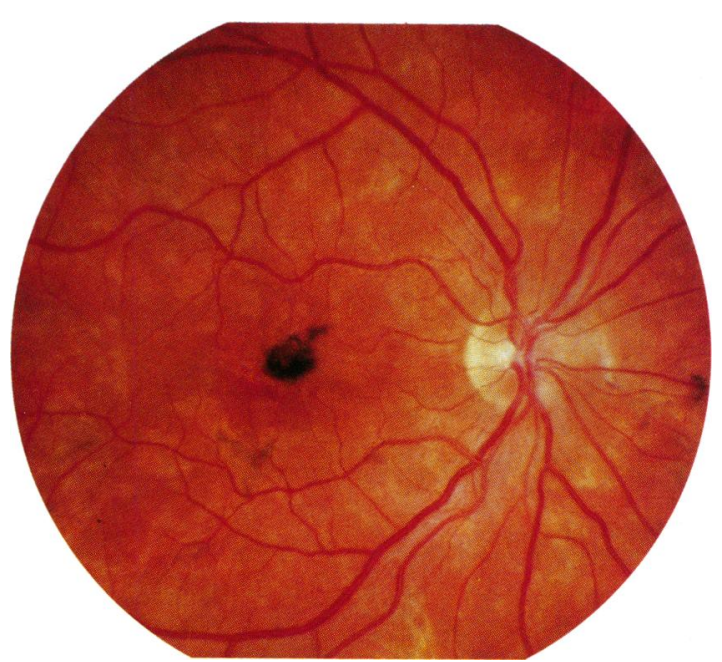

Fig. 8 Fundal appearance eight months after presentation. Note the pigmented macular scar. 
retinal vein occlusion has not been previously reported in APMPPE. The explanation of this may be that many cases of APMPPE are asymptomatic unless there is macular involvement, and when it is complicated by venous occlusion the fundal features of APMPPE are masked. In some cases the patchy hypofluorescence of the placoid lesions may be interpreted as capillary closure on fluorescein angiography.

The place of steroids in the treatment of APMPPE is unproved. A recurrence following withdrawal of steroids has been reported. ${ }^{26}$ In the case reported here it is notable that the venous occlusion occurred in the week following withdrawal of systemic steroid treatment. If vasculitis is implicated in the pathogenesis of the condition, steroid treatment may well have a role in the prevention of complications.

\section{References}

1 Gass JDM. Acute posterior multifocal placoid pigment epitheliopathy. Arch Ophthalmol 1968; 80: 177-85.

2 Azar P, Gohd RS, Waltman D, Gitter KA. Acute posterior multifocal placoid pigment epitheliopathy associated with an adenovirus type 5 infection. Am J Ophthalmol 1975; 80: 1003-5.

3 Van Buskirk EM, Lessell S, Friedman E. Pigmentary epitheliopathy and erythema nodosum. Arch Ophthalmol 1971; 85: 36972.

4 Deutman AF, Oosterhuis JA, Boen-Tan T, Aan De Kerk AL. Acute posterior multifocal placoid pigment epitheliopathy. $\mathrm{Br} \mathrm{J}$ Ophthalmol 1972; 56: 863-74.

5 Dick DJ, Newman PK, Richardson J, Wilkinson R, Morley AR. Acute posterior multifocal placoid pigment epitheliopathy and sarcoidosis. Br J Ophthalmol 1988; 72: 74-7.

6 Jacklin HN. Acute posterior multifocal placoid pigment epitheliopathy and thyroiditis. Arch Ophthalmol 1977; 95: 995-7.

7 Priluck IA, Robertson DM, Buettner H. Acute posterior multifocal placoid pigment epitheliopathy. Urinary findings. Arch Ophthalmol 1981; 99: 1560-2.

8 Holt WS, Regan CDJ, Trempe C. Acute posterior multifocal placoid pigment epitheliopathy. Am J Ophthalmol 1976; 81: 403 12.

9 Sigelman J, Behrens M, Hilal S. Acute posterior multifocal placoid pigment epitheliopathy associated with cerebral vasculitis and homonomous hemianopia. Am J Ophthalmol 1979; 88: 919-24.

10 Kersten DH, Lessell S, Carlow TJ. Acute posterior multifocal placoid pigment epitheliopathy and late onset meningoencephalitis. Ophthalmology 1987: 94: 393-6.

11 Wilson CA, Choromokus EA, Sheppard R. Acute posterior multifocal placoid pigment epitheliopathy and cerebral vasculitis. Arch Ophthalmol 1988; 106: 796-800.

12 Smith CH, Savino PJ, Beck RW, Schatz NJ, Sergott RC. APMPPE and cerebral vasculitis. Arch Neurol 1983; 40: 48-50.

13 Damato BE, Nanjiani M, Foulds WS. Acute posterior multifocal placoid pigment epitheliopathy. A follow-up study. Trans Ophthalmol Soc UK 1983: 103: 517-22.

14 Gass JDM. Acute posterior multifocal placoid pigment epitheliopathy. A long term follow-up. In: Fine SL, Owens SLQ, eds. Management of retinal vascular and macular disorders. Baltimore: Williams and Wilkins, 1983: 176-81.

15 Savino PJ, Weinberg RH, Yassin JG, Pilkerton AR. Diverse manifestations of acute posterior multifocal placoid pigment epitheliopathy. Am J Ophthalmol 1974; 77: 659-62.

16 Young NJA, Bird AC, Sehmi K. Pigment epithelial diseases with abnormal choroidal perfusion. Am J Ophthalmol 1980; 90: 60718.

17 Murray SB. Acute posterior multifocal placoid pigment epitheliopathy. Not so benign? Trans Ophthalmol Soc UK 1979; 99: 497-500.

18 Hayreh SS. Central retinal vein occlusion. In: Mausolf FA, ed. The eye and systemic disease. St Louis: Mosby, 1980: 223-75.

19 Ryan SJ, Maumenee AE. Acute posterior multifocal placoid pigment epitheliopathy. Am J Ophthalmol 1972; 74: 1066-74.

20 Fishman GA, Rabb MF, Kaplan J. Acute posterior multifocal placoid pigment epitheliopathy. Arch Ophthalmol 1974; 92: 235-8.

21 Kirkham TH, Ffytche TJ, Sanders MD. Placoid pigment epitheliopathy with retinal vasculitis and papillitis. $\mathrm{Br} J$ Ophthalmol 1972; 56: 875-80.

22 Deutman AF, Lion F. Choriocapillaris nonperfusion in acute multifocal placoid pigment epitheliopathy. Am J Ophthalmol 1977; 84: 652-7.

23 Wright BE, Bird AC, Hamilton AM. Placoid pigment epitheliopathy and Harada's disease. Br J Ophthalmol 1978; 62: 609-21.

24 Isashiki M, Koide H, Yamashita T, Ohba N. Acute posterior multifocal placoid pigment epitheliopathy associated with diffuse retinal vasculitis and late haemorrhagic macular detachment. Br J Ophthalmol 1986; 70: 255-9.

25 Hayreh SS. Optic disc vasculitis. Br J Ophthalmol 1972; 56: 65270.

26 Lewis R, Martonyi CL. Acute posterior multifocal pigment epitheliopathy. Arch Ophthalmol 1975; 93: 235-8.

Accepted for publication 9 February 1989. 